\title{
FORMAÇÃO DE JOVENS APRENDIZES-TRABALHADORES: trabalho, acidentes e
} identidades profissionais.

FORMATION OF YOUNG APPRENTICES-WORKERS: work, accidents and professional identities

\author{
Solange Regina Schäffer ${ }^{1}$ \\ Maria Gabriela Silva Martins da Cunha Marinho \\ Júlio Francisco Blumetti Facó ${ }^{3}$
}

\section{RESUMO}

O Programa Jovem Aprendiz oportuniza a formação de jovens em determinada profissão, expandindo seus conhecimentos, por mais limitada que seja a formação profissional. A pesquisa qualitativa descritiva em andamento discute as coerções estruturais emergentes das práticas pedagógicas e dos discursos empregados por instituições formadoras dos aprendizestrabalhadores, Camp e CIEE, parceiras de uma indústria automotiva de São Bernardo do Campo na preparação destes jovens para e no trabalho. Objetivando saber se a formação profissional no trabalho auxiliou um grupo de aprendizes, próximos a concluírem a aprendizagem, a se identificarem com as profissões escolhidas e se o tema acidente do trabalho foi suficientemente abordado, utilizou-se as técnicas de observação direta e dinâmica de grupo guiada por Roteiro de Entrevista. A interlocução sobre as falas dos aprendizes-trabalhadores quanto às suas identificações entre a teoria abordada pelas instituições formadoras e a práxis desenvolvida na indústria automotiva, e o sentido do tema Acidente do Trabalho, é mediada pela sociologia reflexiva de Anthony Giddens (2002). Os resultados apontam que para boa parte dos aprendizes não há correlação entre a parte teórica e a práxis laboral, sentem-se à parte da cultura organizacional da fábrica, reclamam que a disciplina da segurança do trabalho não considera os fatores psicossociais, e preferem ter um emprego ao acertar na escolha da profissão.

Palavras-Chave: Formação para o Trabalho. Identidade Profissional. Jovens AprendizesTrabalhadores. Programa Jovem Aprendiz. Região do ABC Paulista.

\begin{abstract}
The Young Apprentice Program allows the training of young people in a given profession, expanding their knowledge, however limited vocational formation. The descriptive qualitative research underway discusses the emerging structural constraints of pedagogical practices and discourses employed by apprentices-workers training institutions, Camp and CIEE, partners of an automotive industry in São Bernardo do Campo in the preparation of these young for and at work. In order to know if the vocational training in the work helped a group of apprentices, to conclude the learning, to identify themselves with the professions chosen and if the subject of work accident was sufficiently approached, the techniques of direct observation and group dynamics were used guided by Interview Script. The interlocution of the learner-worker speeches as to their identifications between the theory approached by the training institutions

\footnotetext{
${ }^{1}$ Doutoranda em Ciências Humanas e Sociais pela Universidade Federal do ABC (UFABC), ingressante pelo Curso de Doutorado Acadêmico Industrial (DAI), Pedagoga e Mestre em Gestão: solange.schaffer@ufabc.edu.br. ${ }^{2}$ Prof $^{a}$. Dra .do Programa de Pós-Graduação em Ciências Humanas e Sociais da Universidade Federal do ABC (UFABC), Historiadora Social: gabriela.marinho@ufabc.edu.br.

${ }^{3}$ Prof. Dr dos Programas de Graduação em Engenharia de Gestão e Pós-Graduação em Engenharia e Gestão da Inovação (UFABC), Engenheiro e Administrador: julio.faco@ufabc.edu.br.
} Revista Labor Edição Especial 
and the praxis developed in the automotive industry, and the meaning of the Work Accident theme, is mediated by the reflective sociology of Anthony Giddens (2002). The results show that for most of the apprentices there is no correlation between the theoretical part and the labor praxis, they feel apart from the organizational culture of the factory, they complain that the discipline of work safety does not consider psychosocial factors, and prefer to have to employment in choosing the profession

Key Words: Formation at the work. Professional Identify. Yong Apprentices-Workers. Program Young Aprrentice. ABC Region of Paulista.

\section{INTRODUÇÃO}

\subsection{Política pública de aprendizagem}

A política Jovem Aprendiz obriga indústrias a empregar determinada porcentagem de aprendizes - cumprimento à cota aprendizagem - de acordo com o número de funcionários que necessitem qualificação profissional. Em contrapartida é direito dos aprendizes o recebimento do salário mínimo-hora, registro em carteira de trabalho, contrato de trabalho não superior a 2 anos, e formação técnica-profissional metódica que garanta o desenvolvimento de atividades teóricas e práticas em empresas, organizadas em tarefas de complexidade progressiva, das mais fáceis às mais complexas, na realização da prática laboral.

A lei de aprendizagem de 1943 determinou a contratação de 5\% de aprendizes sob o total de funcionários que deveriam ser formados pelo Senai (BRASIL, 1943). Outras pequenas alterações na lei de 1943 foram feitas, porém, de maior impacto foi a lei de 2000 que amplia a cota aprendizagem para $15 \%$ e expande a formação técnica-profissional metódica às Escolas Técnicas de Educação e Entidades sem Fins Lucrativos (BRASIL, 2000). Pontos importantes da lei de 1943 foram mantidas pelas tímidas reformulações legais posteriores: aos menores de 18 anos, proibido o trabalho noturno e em atividades insalubres e de periculosidade.

Os anos 1990, marcado pela política neoliberal de expansão da globalização, a vigência de um Estado mínimo e a ampliação da terceirização nas relações de trabalho, permitiu que Organizações Não-Governamentais (ONGs) contratem aprendizes como mão-de-obra terceirizada e barata às empresas, afinal jovens sem experiência estão em fase de aprendizagem, e forneçam o conteúdo teórico como parte da formação profissional dos aprendizes.

O avanço da lei de 2000 em reconhecer a formação profissional das ETECs como uma via direta de contratação de aprendizes que estejam matriculados em cursos nestas escolas, pouco mudou a preferência das empresas em terceirizar essa contratação via ONGs. Assim, as tímidas alterações na lei da aprendizagem nas últimas décadas são direcionadas sob o único e 
legítimo objetivo de corrigir detalhes que atrapalham a funcionalidade do sistema capitalista de reprodução entre capital-trabalho, sem alterar a lógica (LOMBARDI; SAVIANI, 2005).

Se não bastasse, a adoção do modelo pedagógico ultrapassado baseado nas séries às metódicas criado pelo Senai, os governos Lula (BRASIL, 2005) e Dilma (BRASIL, 2016) deram continuidade de abertura das ONGs na contratação de aprendizes e formação destes, atitudes contraditórias às ideologias propaladas por estes dois últimos governos.

ONGs como o Greenpeace ganhou elevada estima por suas ações voluntárias em favor do desenvolvimento sustentável natural e humano. Mas, nem todas ONGs atuam com políticas e éticas coerentes e consistentes como as do Greenpeace, e quando se fala em educação brasileira com atuação mínimo do Estado é de se abismar sob quais experiências e práticas pedagógicas, comprometimento ético e político ONGs se legitimam a educar os mais vulneráveis? Sob o pretexto de docilizar os jovens trabalhadores à lógica capitalista?

Regina Novaes e Paulo Vanucci (2004) citam que em nome da ética que a população transfere à ação voluntária às pessoas carentes, ONGs ganham legitimidade e simpatia sem nenhuma delegação expressa dos sujeitos sociais para que estas exercitem seu papel. Os autores citam que enquanto o Estado se ausenta da efetividade no desenvolvimento das políticas públicas, seus benefícios são diretamente aquinhoados pelas ONGs sem que suas ações pontuais respondem às expectativas dos sujeitos sociais nelas depositada.

Assim, ONG's como o Centro de Formação e Integração Social (Camp) e o Centro de Integração Empresa-Escola (CIEE), instaladas na Região do $\mathrm{ABC}$, ganham simpatia, a primeira por seu assistencialismo aos jovens vulneráveis e suas famílias, fundada por um grupo de rotarianos e, o segundo, pela facilitação de indicação ao emprego nas indústrias de jovens que queiram se inserir no mercado de trabalho, respaldado pela Fundação Roberto Marinho.

E qual o modelo educacional destas duas ONGs, objeto de estudo deste trabalho. Será o de replicar os valores sociais de perpetuação das classes sociais mais abastadas? Educar para que tipo de trabalho, como e sobre quais princípios? Estas ONGs estão preparadas para articular os conteúdos sobre o tema saúde e segurança no trabalho (SST) a práxis desses jovens, ainda em fase de maturidade física, psicológica e emocional nas indústrias e fábricas?

O tema SST é pertinente e necessário, pois o Brasil é um dos países recordistas em acidentes do trabalho, incluindo adolescentes e jovens (MPS, 2015). A naturalização da cultura de uso de adolescentes ou jovens como aprendizes e mão-de-obra barata pelo sistema capitalista, e ainda, a culpabilização do trabalhador pelo próprio acidente descendem do modelo utilizado às épocas das primeiras e segundas revoluções industrias. 
Embora o Ministério do Trabalho sugira que todas as instituições formadoras de aprendizes abordem o conteúdo "Direitos trabalhistas e previdenciários, saúde e segurança no trabalho", não há por parte desse órgão estudos aprofundados e uma sistematização dos dados quanto a articulação teórica dos conteúdos ministrados e as tarefas realizadas pelos aprendizes.

Os temas sugeridos pelo Ministério do Trabalho compreendem: 1- Normas Regulamentadoras (NRs) de SST; 2- Direitos e deveres de empregadores e trabalhadores em relação à SST; 3- Prevenção de acidentes e doenças relacionadas ao trabalho, controle médico de saúde ocupacional (PCMSO) e dos riscos ambientais (PPRA); ergonomia; equipamentos de proteção individual (EPIs); 4- A Comissão Interna de Prevenção de Acidentes (CIPA); 5 Higiene e conforto nos locais de trabalho; 6- O Programa de Alimentação do Trabalhador.

Sob um modelo mais desumano, hostil e sem proteção social, Alexis de Tocqueville (1979) relatou em 1858 acidentes de trabalho com crianças em fábricas durante suas viagens pela Inglaterra e Irlanda na segunda revolução industrial, entrevistando um trabalhador de uma indústria de tecelagem, pai de duas meninas menores de idade que também trabalhavam lá;

Pergunta: A que horas vão as menores à fábrica?

Resposta: Durante seis semanas foram às três horas da manhã e voltaram às dez horas da noite.

Pergunta: Quais os intervalos concedidos durante as dezenove horas, para descansar ou comer?

Resposta: Quinze minutos para o desjejum, meia hora para o almoço e quinze minutos para beber.

Pergunta: Tinha muita dificuldade para despertar suas filhas?

Resposta: Sim. A princípio, tínhamos que sacudi-las para despertá-las e se levantarem, bem como vestirem-se antes ir ao trabalho.

Pergunta: Quanto tempo dormiam?

Resposta: Nunca se deitavam antes das onze horas, depois de lhes dar algo que comer. Pergunta: Então, somente tinham quatro horas de repouso?

Resposta: Escassamente quatro.

Pergunta: Quanto tempo durou essa situação?

Resposta: Umas seis semanas.

Pergunta: Trabalhavam desde as seis horas da manhã até às oito e meia da noite?

Resposta: Sim, é isso.

Pergunta: As menores estavam cansadas com esse regime?

Reposta: Sim, muito. Mais de uma vez ficaram adormecidas com a boca aberta. Era preciso sacudi-las para que comessem.

Pergunta: Suas filhas sofreram acidentes?

Resposta: Sim, a maior, a primeira vez que foi trabalhar prendeu o dedo em uma engrenagem e esteve cinco semanas no hospital de Leeds.

Pergunta: Recebeu o salário durante esse tempo?

Resposta: Não, desde o momento do acidente, cessou o salário.

Pergunta: Suas filhas foram remuneradas?

Resposta: Sim, ambas.

Pergunta: Qual era o salário em semana normal?

Resposta: Três shillings por semana, cada uma (TOCQUEVILLE, 1979, p. 107) 14. 
À época, a educação aos filhos de pobres era reservada às igrejas protestantes por meio da educação profissionalizante e aos filhos de operários, o aprendizado fabril ministrado dentro das próprias fábricas pelos mestres de ofício, quem detinha o direito de punir com severos castigos os aprendizes que dormiam durante o aprendizado ou não cumpriam as tarefas. Em tempos atuais, os dias de trabalho perdidos por causa de acidentes são geralmente indenizados, contudo, os sofrimentos e pressões psicológicas pelo ainda vigente erro humano perdura.

O paradigma do erro humano é empregado em quase todo o mundo pelo sua facilidade e tendenciosidade em achar o culpado pelo acidente: o trabalhador ou falha humana muito comum em acidentes aéreos. Muito provavelmente ONGs não fogem à essa regra, e nem a fácil abordagem de replicar os modelos de relações sistêmicas capitalistas consolidados a partir do conceito, conforme aponta Anthony Giddens (1997), de que todas as estruturas sociais são simultaneamente facilitadora e coerciva do conhecimento. István Mészáros (2005) traz uma profunda reflexão sobre utilizar o conhecimento como auto-transformação humana:

\begin{abstract}
A aprendizagem é a nossa própria vida, desde a juventude até a velhice. Seria o conhecimento o elemento necessário para transformar em realidade o ideal da emancipação humana, em conjunto com uma firme determinação e dedicação dos indivíduos para alcançar a auto-emancipação da humanidade, ou será, a adoção pelos indivíduos, de modos de comportamento que apenas favorecem a concretização dos objetivos reificados do capital? (MÉSZÁROS, 2005, p. 47).
\end{abstract}

Será então que as ONGs formadoras de aprendizes para o trabalho contribuem para suas emancipações profissionais ou os treinam que seus comportamentos sejam de aceitação as regras já institucionalizadas? Marise Nogueira Ramos (2006) concebe o processo de formação humana como produtora do sentido do trabalho, transformadora e transformada pelas relações econômicas e sócio-afetivas, subjugado ao modo de produção de bens e produtos, onde as potencialidades humanas - físicas, intelectuais e emocionais - são alienadas ao próprio trabalhador e apropriadas pelo capitalismo como mercadoria da força de trabalho.

Atualmente, o processo de formação está atrelado aos modelos de competência intimamente ligados à cultura institucional de cada organização reprodutora do conhecimento, habilidades e ética social. Para José Lombardi e Dermeval Saviani (2005), as novas configurações das competências individuais na conquista de posição no mercado de trabalho e empregabilidade se dá pela suposta satisfação à alienação crítica e a lógica econômica arraigada aos modelos educacionais, ou à sua adaptação à cultura institucionalizada.

\title{
Revista Labor Edição Especial
}




\subsubsection{Inserção, formação e identidades profissionais}

A política de aprendizagem objetiva a inserção formal no trabalho de jovens entre 14 e 24 anos e a formação profissional como oportunidade às organizações formarem sua própria mão de obra, e quando possível, efetivarem esses jovens após a finalização da aprendizagem. Embora o processo de inserção de aprendizes no mercado não ser objetivo deste trabalho é importante destacar que aprendizes são utilizados como mão de obra temporária, barata, terceirizada, pois a legislação assim permite.

Sob a premissa que todos têm direito a construir identidades e subjetividades a partir doo trabalho, Alexandre Soares (2010) participou de uma pesquisa junto aos jovens de comunidade de baixa renda do Rio de Janeiro para conhecer os obstáculos enfrentados para a inserção. Um desses obstáculos é a projeção dos pais para que os jovens cumpram etapas previamente previstas como estudar, trabalhar e constituir sua própria família. Outro integrante da equipe desta pesquisa, o americano Malcom Bush, ressalta que inserção juvenil em seu país e na Europa Ocidental requer estratégias de qualificação em computação e tecnologia, familiaridade com códigos de conduta das empresas, e aproximação com os empregadores.

Obviamente, computação e tecnologia são fatores primordiais ao desenvolvimento das competências de jovens como um todo, e a familiaridade com a cultura institucional é imprescindível para a adequada evolução profissional dos jovens. Contudo, a aproximação com empregadores não garante projeção e inspiração profissional aos aprendizes, principalmente se há grandes diferenças socioeconômicas entre os atores. Assim, a vivência no trabalho e a formação recebida é quem auxiliará ou não os aprendizes a se identificarem profissionalmente.

A identidade social é traçada pela trajetória um indivíduo, construída e reconstruída a partir de sua profissão e escolaridade, repleta de sentido coerente e satisfatório. Para Giddens (2002), somente a partir da diferenciação da divisão do trabalho no mundo moderno, com a especialização de tarefas, é que indivíduos se tornaram pontos de atenção: se refere à divisão do trabalho: a especialização de tarefas, baseada nos modelos das competências, é quem diferencia, pune ou destaca um trabalhador de outro.

Contudo, ao considerar a realidade brasileira com altos índices de desemprego, principalmente jovens, desigualdades socioeconômicas e precária formação básica, é possível que esses jovens tenham dificuldades em construir uma identidade profissional clara e organizada, segundo a concepção de Giddens (2002). 
Giddens (1997) afirma que indivíduos possuem capacidade para transformar a práxis ou somente reproduzir o que já é dado para manter a continuidade do que é produzido material e socialmente, pois, estruturas sociais. Por mais poder de transformação de regras e recursos implícitos na reprodução material e social, estas fixam limites motivacionais e racionais aos atores, para que as coisas funcionam de acordo com o escopo de desenvolvimento produtivo.

Para Giddens (1997), o escopo produtivo compreende produtos, normatizações e fornecedores, assim, toda a estrutura de modos de coerção - sanções, ou seja, desaprovações, em menor ou maior grau, podem levar distintos grupos ao isolamento cultural diante do que é designado como princípios estruturais: quanto mais as instituições se fixam no tempo-espaço, mais ela s resistem à manipulação ou mudanças realizadas pelos agentes sociais.

\subsubsection{Os aprendizes-trabalhadores na região do $\mathrm{ABC}$}

A re/inauguração da Via Anchieta em 1947. Antônio de Almeida (2008) relata a utilização de menores a partir dos 10 anos de idade como mão-de-obra fabril como parte dos 46,3 mil trabalhadores contratados por grandes indústrias automotivas multinacionais, instaladas nas principais cidades de Santo André, São Bernardo do Campo e São Caetano do Sul.

Outras fábricas de médio e pequeno porte, fornecedoras de insumos - autopeças, mecânicas, elétricas e metalúrgicas - também surgiram provocando intenso processo migratório para vilas adjacentes da região, formada hoje por sete municípios - Diadema, Mauá, Ribeirão Pires e Rio Grande da Serra (ALMEIDA, 2008). Com a industrialização, o CIEE e o Camp se instalaram nesta região, o primeiro, grupo pertencente à Fundação Roberto Marinho, têm filiais em São Caetano do Sul e Santo André. O Camp chegou à região em 1972 com um grupo de rotarianos e atualmente tem filiais em Ribeirão Pires e Rio Grande da Serra.

A parceria dessas ONGs com empresas da região, estas formalizam o contrato de trabalho, fazem o registro na carteira e assumem o recolhimento das férias, $13 \%$ salário e INSS, e ministram a carga teórica da formação profissional, assim, justificam o repasse de verba do governo federal e entram para a estatística do Ministério do Trabalho como instituição que contribui para a inserção de jovens no mercado. À empresa cabe supervisionar as atividades práticas exercidas pelos aprendizes, alimentação e transporte fretado: é uma terceirização sem maiores custos e sem a obrigatoriedade de contratação posterior à aprendizagem. 
O CAMP é voltado a assistência social de jovens em situação de vulnerabilidade social com renda per capita familiar menor que 2 salários mínimo e visa fortalecer o desenvolvimento de atitudes e habilidades cidadãs. Ao se inscrever no Programa Jovem Aprendiz, o adolescente cursa a Formação Básica para o Trabalho por mais ou menos 6 meses de duração, e após aprovação no curso, aguarda convocação para participar de entrevistas em empresas parceiras.

No CIEE, o currículo enviado pelo jovem é analisado e se o perfil se adequa às exigências de alguma empresa parceira, o candidato é chamado para e entrevista e depois é encaminhado às empresas: boa parte dos aprendizes são indicados por funcionários das próprias empresas parceiras. Esta ONG acredita que seu método de formação do aprendiz estimula a autonomia e pró-atividade do jovem, sob o slogan “Aprendiz Legal”, o jovem assume o papel de agente no desenvolvimento de sua própria carreira e de colaborador da empresa que o recebe, canalizando sua energia, criatividade e ousadia à renovação de ideias, estruturas e processos.

Para a grande maioria dos pouco mais de 100 (cem) de aprendizes-trabalhadores ${ }^{4}$ auxiliares administrativos Camp e CIEE, entre 17 e 19 anos, o contrato de aprendizagem é sua primeira experiência laboral formal. Os primeiros têm tempo de vigência de 15 meses, jornada de 06 horas-diárias e salário médio de R \$ 580,00, os segundos, 24 meses, jornada de 04 horasdiárias, remuneração média de $\mathrm{R}$ \$ 520,00, transporte fretado da empresa no deslocamento entre residência-trabalho ou trabalho-faculdade, e refeições feitas nos restaurantes da indústria.

\section{OBJETIVO}

O objetivo da pesquisa realizada em 2015 junto a um grupo de auxiliares administrativos Camp e CIEE, lotados em uma indústria automotiva, ambas do ABC, analisou se a formação recebida auxiliou esses aprendizes, próximos a concluírem a aprendizagem, a se identificarem com a profissão escolhida e se o tema acidente do trabalho foi suficientemente abordado.

Os aprendizes auxiliares administrativos são bem distribuídos quanto à origem, Camp ou CIEE, sexo e etnia - o número de aprendizes pode variar, pois depende do número de funcionários da empresa - a grande maioria residem no $\mathrm{ABC}$ e têm nível médio completo, aqueles em fase de conclusão cursavam o $3^{\circ}$ ano em escola estadual, e quase a metade deles cursam faculdade a noite nas cidades de São Bernardo do Campo e Santo André.

\footnotetext{
${ }^{4}$ Expressão escolhida pela pesquisadora para qualificar a formação profissional desses aprendizes que mais trabalham 4 vezes por semana na indústria automotiva, que estudam - somente 1 dia na semana. Revista Labor Edição Especial 
A pesquisa teve como problema, o processo de formação no trabalho contribui para a identificação profissional com a profissão escolhida, a partir dos conteúdos teóricos abordados pelo Camp e CIEE? A pesquisa teve por hipótese a fato dos aprendizes possuírem prévia identificação com a profissão escolhida ao se inscrevem no Jovem Aprendiz, e que essa identidade profissional poderia sofrer mudanças ao longo do processo de aprendizagem.

Parte-se da premissa que a aprendizagem permite aos aprendizes vivenciarem todas as facetas da profissão escolhida, expressarem suas impressões quanto o que é necessário melhorara, e ainda sentirem-se parte das corporações, pois a etapa da formação profissional de aprendizes compreende a fase mais importante da política Jovem Aprendiz: a) conteúdos teóricos, conceitos sobre organização do trabalho, condições de trabalho, formas de regulação de conflitos e gestão da força do trabalho; b) parte prática a realização rotineira e sistematizada das atividades laborais em distintos setores administrativos da empresa.

A empresa pesquisada tem por queixa a evasão de aprendizes durante a vigência do contrato de trabalho. Embora com índice baixíssimo de evasão, a empresa alega todo um dispêndio de tempo e de logística voltados à contratação dos jovens evadidos. Assim, conhecer se a formação propiciou a identificação dos aprendizes com a profissão escolha e quais as opiniões dos aprendizes sobre o processo de formação, contribuirá com um feedback à empresa sobre ajustes e melhorias que podem ser efetivadas, evitando novas evasões.

\section{METODOLOGIA}

A pesquisa qualitativa descritiva se utilizou de amostra não probabilística por conveniência, ou seja, a amostra foi definida de acordo com interesse escolhido pelos orientadores e a pesquisadora. Como procedimento de pesquisa foi realizada revisão bibliográfica sistematizada dos temas formação profisssional de aprendizes, inserção de jovens no mercado de trabalho, política pública Jovem Aprendiz e acidentes do trabalho com menores.

Como estratégias da pesquisa foram utilizadas as técnicas Observação Participante, aplicação de uma dinâmica de grupo junto a um grupo de aprendizes auxiliares administrativos próximos ao término da aprendizagem, norteada por 4 questões centrais, e realização de reunião junto aos coordenadores da empresa, Camp e CIEE (MINAYO, 2004).

Devido ao espalhamento dos aprendizes por distintas áreas administrativas da empresa, decidiu-se saber onde e em que momento poderia encontrar o maior número de aprendizes reunidos. Supervisionados por distintos orientadores, almejou-se ter uma prévia das opiniões quanto à identificação ou não dos aprendizes com a profissão escolhida, para um 
melhor aprofundamento das fases seguintes da pesquisa de doutorado. Felizmente, um projeto da empresa realizado anualmente aos sábados por tempo integral, ministrado por uma terceira entidade contratada, se encontrava em fase de finalização.

Por meio deste projeto eram oferecidos cursos variados a determinado número de aprendizes Camp e CIEE que se inscreveram e foram aprovados num processo seletivo interno: tratava-se de uma qualificação profissional a mais para a fase de aprendizagem. Participavam do curso cerca de quarenta aprendizes. Solicitei então reunião junto a coordenadora do projeto da empresa e após explicar a proposta da pesquisa tive acesso à coordenação da outra terceira via, quem me autorizou a conversar com os professores que ministravam as aulas.

Com permissão dos professores para o acesso às aulas, foi utilizada a técnica de observação direta para assistir algumas aulas teóricas e apresentações de trabalhos feitas pelos aprendizes. A técnica consiste em observar as mensagens transmitidas pelos professores, as reações dos alunos frente às mensagens passadas, e a anotação sistematizada das informações passadas e reações não verbais expressas por professores e aprendizes.

Depois de dois sábados assistindo e tendo contato com os aprendizes, fui autorizada por uma docente, utilizar uma aula dela para a aplicação de uma dinâmica de grupo. Antes da data marcada da dinâmica foi elaborado um roteiro de quatro questões que nortearam o debate junto aos aprendizes. Para cada questão a ser debatida ao que chamei de reflexão, estabeleci uma premissa, ou seja, suposição que serviram de base para decidir a necessidade de serem aprofundadas ou não nas etapas posteriores da pesquisa aplicada, e um objetivo.

No último dia dos cursos ministrados aos sábados, foi cedido o tempo de 40 minutos de determinada aula para aplicação da dinâmica de grupo junto a 26 alunos - 15 CAMP e 11 CIEE. Com questões centrais previamente elaboradas foram destinados 10 minutos para discussão de cada questão provocada. Devido ao pouco tempo para escrever cada uma das respostas, utilizei o quadro magnético da sala e a caneta hidrográfica, divide-o em quadro partes verticais e no cabeçalho anotei cada questão, e as respostas foram anotadas em forma de itens.

1) Premissa A: a política Jovem Aprendiz objetiva preparar jovens para o trabalho, assim, próximos à finalização do contrato de aprendizagem, esses aprendizes encontram-se bem preparados quanto às habilidades pessoais e competências técnicas para atuarem no mercado?

Objetivo A: conhecer se os aprendizes sentem-se preparados para ocuparem a vaga de estagiários dentro da indústria onde realizam a prática da aprendizagem ou em outra empresa. 
Reflexão A: Vocês se sentem adequadamente preparados para serem contratados por esta empresa como estagiários ou pelo mercado de trabalho externo? Se não, o que falta?

Respostas A: Por unanimidade, todos aprendizes afirmaram não estar preparada para o mercado de trabalho, pois a carga horária teórica é insuficiente, impedindo o aprofundado teórico sobre administração empresarial, e que falta planejamento da parte teórica da aprendizagem como um todo. Um aprendiz CIEE disse que seus colegas devem se dedicar ao curso.

2) Premissa B: Orientadores dos aprendizes tem por compromisso a acompanhar as atividades práticas desses jovens durante o processo de aprendizagem, articulando a teoria aprendida com a práxis laboral, além de contribuir com a emancipação de valores sociais.

Objetivo B: Saber a opinião dos aprendizes se seus orientadores acompanham e instruem de forma suficiente seus processos de aprendizagem.

Reflexão B: Seus orientadores auxiliaram para incrementar o desenvolvimento profissional de vocês ao longo da aprendizagem? O que não funcionou? Quais sugestões de melhoria?

Respostas B: Grande parte afirmou que os orientadores contribuíram com o desenvolvimento profissional, mas alguns reclamaram da falta de compromisso do orientador com atividades extra-empresa, que a comunicação entre os orientadores e os aprendizes deveria ser melhorada, e que o papel desses deveria ser melhor definido. Um aprendiz Camp ressaltou deveria ter ex-aprendizes, atuais funcionários da empresa, como orientadores.

3) Premissa C: A boa articulação entre conteúdos teóricos apreendidos e atividades práticas são fundamentais para uma satisfatória formação profissional.

Objetivo C: Saber se houve articulação entre os conteúdos teóricos abordados pelo Camp e CIEE e as atividades práticas desenvolvidas na empresa auxiliaram na sua formação profissional.

Reflexão C: Acreditam que houve boa articulação entre conteúdos teóricos abordados pelo Camp e CIEE e as atividades práticas desenvolvidas na empresa?

Respostas C: Boa parte afirmou que de modo geral sim, um aprendiz Camp reclamou que foi inserido na empresa sem antes fazer o curso de redação ministrado, fato que prejudicou seu desenvolvimento profissional, e que esse tipo de aula seja ministrado aos sábados. No entanto, muitos reclamaram que as palestras: os palestrantes não foram dinâmicos ao apresentarem os assuntos. As sugestões de melhoria compreenderam acrescentar palestra com o tema Postura Profissional, e usar o tempo de uma palestra para escolher eventos culturais 
e não recreativos, relacionados à aprendizagem administrativa, como por exemplo, visita a feira da World Skills. Um aprendiz Camp sugeriu que ex-aprendizes, atuais funcionários da empresa, palestrassem nas ONGs Camp e CIEE para mostrar o caminho que percorreram para tornaremse efetivos.

4) Premissa D: Atividades técnicas, pedagógicas, educativas e culturais abordadas ao longo da aprendizagem contribuíram para o desenvolvimento técnico e social dos alunos.

Objetivo D: Investigar se as atividades práticas e teóricas - atividades, aulas, palestras eventos culturais - auxiliaram os aprendizes a se identificarem com a profissão auxiliar administrativo.

Reflexão D: Vocês escolheram a profissão auxiliar administrativo. Vocês se identificaram com essa carreira ou pretendem seguir outro caminho?

Respostas D: Grande parte afirmou que não, pois as aulas do CIEE e CAMP são muito teóricas e não apresentam interlocução entre teoria e prática. Alguns destacaram que os assuntos abordados pelo Camp não têm coerência entre, são muito confusos e vagos, centrado apenas no cumprimento das funções e menos no desenvolvimento de habilidades e competências pessoais.

A técnica observação participante mostrou-se eficiente para compreender as mensagens transmitidas pelos professores, as reações dos alunos frente às mensagens passadas, e a anotação sistematizada das informações passadas e reações não verbais expressas por professores e aprendizes, podendo ser largamente utilizadas em pesquisas qualitativas.

A dinâmica em grupo foi importante para aprofundar outros aspectos que serão aprofundados nas fases posteriores da pesquisa de doutorado, mas o tempo de 40 minutos se mostrou insuficiente para um grupo de 26 alunos, pois, geralmente eram sempre os mesmos que respondiam as provo ações, enquanto outros por medo de se expressar ou por timidez não se pronunciaram, mesmo sob provocação da pesquisadora.

\section{CONCLUSÃO}

As observações participantes feitas pela pesquisadora retrataram que os conteúdos ministrados pelo Camp estão centrados nas regras sociais que os aprendizes devem cumprir: o respeito às hierarquias e regras institucionais, o saber se portar no trabalho e na sociedade etiquetas à mesa, modo de falar, se vestir, cuidado com o vocabulário. O tema SST é abordado de forma isolada sem profundidade que o tema exige e desconexo da realidade do aprendiz.

\section{Revista Labor Edição Especial}

Fortaleza/CE, Novembro de $2017 \quad$ Vol. 02, nº 18, p. 120-134 ISSN 1983-5000 
O CIEE possui abordagem mais técnica da profissão auxiliar administrativo quanto as habilidades e competências necessárias para ser um aprendiz nesta área, mas erra ao misturar aprendizes de 14, 18 e 24 anos na mesma sala de aula, não respeitando a fase de desenvolvimento intelectual e emocional, abordando temas muito aquém para os mais novos que não conseguem acompanhar a teoria, ou enfadonho aos mais velhos.

Devido à indisponibilidade ou falta de interesse da empresa na contratação desses aprendizes após finalização do contrato de trabalho, a formação desses jovens não é acompanhada pela empresa: possível contratação se restringe a vaga de estágio para aqueles que cursam o terceiro grau, em tema de interesse da empresa. O aprendiz CAMP apresenta vulnerabilidade social, enquanto o CIEE contrata candidatos indicados por funcionários da empresa, fato que pode privilegiar estes para a vaga de estágio em detrimento aos outros.

Quanto ao objetivo principal da pesquisa averiguou-se que a formação recebida pelos aprendizes, próximos a concluírem a aprendizagem, não auxiliou na identificação destes com a profissão auxiliar administrativo, deixando uma enorme insegurança em assumir novo posto de trabalho em outras empresas, após a finalização do contrato de aprendizagem. Talvez estes sejam os principais motivos que levam alguns aprendizes à evasão da aprendizagem.

Os conteúdos teóricos do Camp e CIEE desconexos da prática labora, a carga horária teórica insuficiente desses conteúdos, a falta de comprometimento dos orientadores da empresa no acompanhamento do processo de formação profissional, e a ausência de articulação entre as ONGs e a empresa no desenvolvimento da aprendizagem como um todo contribuíram para a não identificação profissional dos aprendizes com a profissão auxiliar administrativo.

Resgatando o conceito de identidade de Giddens (2002), a trajetória profissional desses aprendizes foi construída com muitos valores e aprendizado, mas a falta de sentido, coerente e satisfação entre conteúdos teóricos e práticas realizadas não proporcionou um lastro adequado para a identificação profissional de todos deste grupo participante da pesquisa. A hipótese inicial de que os aprendizes possuem prévia identificação com a profissão escolhida ao se inscrevem no Jovem Aprendiz foi refutada, pois para a grande maioria a profissão é o que menos importa, mas sim a oportunidade de ter um emprego em uma indústria tão renomada.

Quanto ao tema SST alguns aprendizes Camp relatam ansiedade por sofrerem bullying dos aprendizes CIEE devida à diferença socioeconômico e reclamam que os fatores psicológicos no trabalho não são abordados no conteúdo de SST. Essa situação demonstra falta de preparo dos orientadores em resolver essa situação. Embora boa parte dos aprendizes expressarem alegria pelos conhecimentos adquiridos e conquistas de novas amizades, as 
potencialidades intelectuais e emocionais não são respeitadas pelas ONGs, uma vez que são alienadas aos próprios aprendizes, inconsciente ou conscientemente norteadas.

Não se trata de ser contra a cota aprendizagem, já que no Brasil essa é uma das poucas formas dos jovens vulneráveis terem a oportunidade de vivenciar uma profissão, experenciar projetos, aumentar a rede de relacionamentos pessoais, ter um registro formal de trabalho e receber por isso, mas sim se indignar com a incipiente monitoração por parte do Estado e seus respectivos órgãos federativos, quanto aos conteúdos ministrados, da forma e sob quais discursos essas ONGs preparam os jovens para e no trabalho.

\section{REFERÊNCIAS}

ALMEIDA, A. Experiência Políticas no ABC Paulista: lutas e práticas culturais de trabalhadores. Uberlândia: EDUFU, 2008. 300 p. ISBN 978-85-7078-206-9.

BRASIL. Decreto-Lei no 5.452, de 01 de maio de 1943. Aprova a Consolidação das Leis do Trabalho. Diário Oficial. Brasília, DF, 09 ago. 1943. Seção 1, p. 11.937-11.984.

Lei $n^{\circ} 10.097$, de 19 de dezembro de 2000. Altera dispositivos da Consolidação das Leis do Trabalho - CLT aprovada pelo Decreto-Lei n. 5.452, de $1^{\circ}$ de maio de 1943. Diário Oficial da União, Poder Executivo, Brasília, DF, 20 dez. 2000. Seção 1, p. 1-2.

Decreto-Lei $n^{\circ}$ 5.598, de 01 de dezembro de 2005. Regulamenta a contratação de aprendizes e dá outras providências. Diário Oficial da União, Poder Executivo, Brasília, DF, 02 dez. 2005. Seção 1, p. 2-4.

Decreto $\mathrm{n}^{\mathrm{o}} 8.740$, de 04 de maio de 2016. Altera o Decreto $\mathrm{n}^{\circ} 5.5 .98$, de $1^{\circ}$ de dezembro de 2015, para dispor sobre a experiência prática do aprendiz. Diário Oficial da União, Poder Executivo, Brasília, DF, 05 mai. 2016, Seção 1, p. 4-5.

GIDDENS, A. Modernidade e Identidade. Rio de Janeiro: Zahar. Trad. Plínio Dentzien. $2002.232 \mathrm{p}$.

Novas Regras do Método Sociológico: Trajectos Lisboa: Gadiva. 2. e. 1997. 193

p.

LOMBARDI, J. C.; SAVIANI, D; SANFELICE, J. L. Capitalismo, Trabalho e Educação. Campinas: Autores Associados. 3. Ed. 2005. 163 p.

MÉSZAROS, I. A Educação para Além do Capital. São Paulo: Boitempo, 2005. Trad. 77 p.

MINAYO, M. C. S. (Org.). Pesquisa Social: Teoria, método e criatividade. 23. ed. Rio de Janeiro: Vozes, 2004. 80 p. (Coleção Temas Sociais). ISBN 85-326-1145-1.

MINISTÉRIO DA PREVIDÊNCIA SOCIAL. Anuário Estatístico da Previdência Social (AEPS). Brasília: MF/DATAPREV, 2015. 918 p. Disponível em:< 
http://www.previdencia.gov.br/wp-content/uploads/2015/08/AEPS-2015-FINAL.pdf>. Acesso em: 11 jul. 2017.

NOVAES, R; VANNUCHI P (Org.) Juventude e Sociedade: Trabalho, Educação, Cultura e Participação. São Paulo: Fundação Perseu Abramo. 1 Ed, 2004. 303 p.

RAMOS, M. N. A Pedagogia das Competências: Autonomia ou Adaptação? São Paulo: Cortez, 2006. 3. Ed. 320 p.

SOARES, A. B. (Org.) el al. Juventude e Elos com o Mundo do Trabalho: Retratos e Desafios. São Paulo: Cortez. 2010. 110 p.

TOCQUEVILLE, A. Journeys to England and Ireland. New Jersey: Arno Press, 1979. 255 p. 